\title{
A REVIEW ON HARSHRINGAR-AN IMPORTANT MEDICINAL PLANT
}

\author{
Ruchita Shrivastava $^{*}$, Ajay Kumar Bharadwaj ${ }^{* *}$ \\ *Research Schoar, Govt. N.M.V. Hoshangabad (MP), India \\ ${ }^{* *}$ Department of Biotechnology, Institute for Excellence in Higher Education, Bhopal India
}

\begin{abstract}
Ayurveda is one of the oldest system of medicines that uses plants and their extracts for the treatment and management of various diseased states. Medicinal plants are being widely used either as single drug or in combination in health care delivery system. Nyctanthes arbor-tristis is commonly known as Indian Harshringar (family-oleaceae) is an important medicinal large shrub. It contains various phytoconstituents belonging to the categories of glycosides,alkaloids, essential oils,tannins etc.It has been reported as useful in sciatica,arthritis,fever,asthma,diabetes,cancer,etc.Several studies are being carried towards its activities like antibacterial,antifungal,immuno-modulatory,antipyretic,anti-oxidant,hepato-protective properties. With all these potential benefits, this review is carried out to explore the hidden potential and its uses. This present review explores the published scientific literature to compile all the traditional and scientific datas of Nyctanthes arbor-tristis.
\end{abstract}

KEYWORDS:- Nyctanthes arbor-tristis, Oleaceae,Indian Harshringar.

DOI: $10.7176 / \mathrm{JNSR} / 9-8-07$

Publication date: April $30^{\text {th }} 2019$

2. INTRODUCTION:- Nyctanthes arbor-tristis is commonly known as Harshringar belonging to the family Oleaceae.The name Nyctanthes means "Night Flowering". It is a shrub or small tree growing to $10 \mathrm{~m}$ tall flaky grey bark.Leaves are opposite,simple,6-12 cm long and 2-6.5 cm broad with entire margines. The flowers are fragrant with a 5-8 lobbed white corolla (petals) with orange red centre which are produced in clusters of 2-7 together with individual flower opening dusk and finishing at down. The fruit is a flat brown heart shapped to round shapped capsule which is $2 \mathrm{~cm}$ in diameter with two sections each containing a single seed.This is a common medicinal plants widely used in Indian system of medicines and also an official drug in Indian pharmacopoeia.

3. MEDICINAL PROPERTIES:- Medicinal properties of Nyctanthes arbor-tristis were described by K.Priya and Deepak Ganjewala(2007),Bansal et al (2012),R.K.Saha et al (2012),Ramadan B.Sopi et al (2013),Vipin Sharma and Amit Marwaha (2011).The leaves are used as antibacterial,antimicrobial,bronchiodilatory,hepatoprotective,anti-diabetic (K.Priya et al ,2007;Bansal et al,2012; Sopi et al,2013;Vipin Sharma and Amit Marwaha,2011). The fruits are used as anti-anxiolytic,antioxidant,diuretic (T.D.Sandhya kumar et al,2012;Shalini Tripathi,2012;D.Sasmal et al,2007).

3. ETHNOBOTANICAL STUDIES:- Ethnobotanical studies on Nyctanthes arbor-tristis revealed its benefits towards various ailments like fever,cough and gastritis (Chiranjibi Pattanaik and Rasmita Das,2007;Bipul Saikia et al,2008). Juices of leaves is used as digestives,antidote to reptiles venome ( P.S. Varier et al,1995;Nadkerni et al,1982). Leaves are also used in the enlargement of the spleen (Kirtikar and Basu,2000) as well as leaf decoction along with honey is used to cure fever,malaria,blood dysentery by the folk peoples of Balasore,Orissa ( R.D.Girach et al,1994). The powdered seeds are used to cure scurfy infection of scalp,piles and skin diseases ( Nadkerni et al,1982;Basu and Kirtikar,2000;R.D.Girach et al,1994).Traditionally the powdered stem bark is given in rheumatic 
joint pain,oil is used for pain in the eyes and with Arjuna bark it is rubbed on the body in internal injury (Basu and Kirtikar,2000). Bark and flower decoction are usually given in malaria fever (R.D.Girach et al,1994).Its flowers are bitter,astringent,carminative,stomachic and used in ophthalmic purposes. The roots are traditionally used as anthelmintics and its decoction is used in enlargement of spleen.Barks are traditionally used as anti-dysentric and antidiarrhoeals. The corolla tubes are formerly used to dyeing silk. Flower extract of Nyctanthes arbor-tristis along with Tagetus erecta shows sunscreen activity (Vaishali Bambal et al,2011). Its combination with Piper nigrum bears antipyretic activity in different dose forms ( N.B.Ghiware and T.M.Nesari,2013).

4. TISSUE CULTURE STUDIES:- Plant tissue culture studies on Nyctanthes arbor-tristis were reported by M.Anis and Anushi A.Jahan(2006),S.Bansal,A.J.Bharti et al (2012),G.R.Rout et al (2007),Champa Rani et al (2012). A.A.Jahan and M.Anis successfully developed an efficient,rapid and reproducible plant regeneration protocol for Nyctanthes arbor-tristis using cotyledonary node explants supplemented by two cytokinnins namely thidiazoron (TDZ) and 6-benzyladenine (BA) to MS-medium. The In-vitro propagation of Harshringar from axillary buds explant on MS-medium was successfully obtained by S.Sasmal with his co-workers. Champa Rani and Sunaina Chawla with co-workers reported about the micropropagation of Harshringar as well as its chemical constitution,biological activities of important compounds,pharmacological actions and medicinal applications. G.R.Rout A.Mahato and S.K.Senapati also achieved rapid shoot multiplication from axillary meristems on MS basal medium supplemented by $1.0-1.5 \mathrm{mg} / 1$ of 6 -benzyladenine (BA), $50 \mathrm{mg} / 1$ of adenine sulphate and $3 \%$ sucrose.

5. CONCLUSION:- The plant Nyctanthes arbor-tristis is one of the most important source of medicinally important constituents widely experimented by scientists. Most of the scientific works have been conducted on the leaves and seeds of Nyctanthes arbor-tristis plant although there are reports abouts using bark powder and root extract in folk medicines. The main thirst of this review is to compile a number of uses of all the parts of plants. So far the major uses have been found on the leave extract of Nyctanthes arbor-tristis including from bitter tonic to digestive, laxative, diuretic, in spleen enlargement, as anti-oxidant,anthelmintic, expectorant,bronchiodialatory, even as anti-dote to reptiles venome. The powered seeds have been used to cure scalp and in piles and skin diseases. Flowers as astringents, carminatives, etc.

From the above study, it is revealed that the leaves of plant Nyctanthes arbor-tristis are extensively exhausted for the study purpose but there is a need to pay attention on the flowers and stem also.

\section{REFERENCES:-}

1] Anis M.,Jahan A.A.,2006,Rapid Multiplication of Nyctanthes arbor-tristis L. through in-vitro Axillary Shoot Proliferation,World Journal Of Agricultural Sciences,2(2);188-192.

2] Bambal Vaishali,Mishra Manisha,Turasker Ashish,2011,Study of Sunscreen Activity of Herbal Cream Containing Flower Extract of Nyctanthes arbor-tristis and Tagetes erecta L.,11(1).

3] Bansal S.,Bharti A.J.,Bansal Y.K.,2012,Efficient In-vitro Regeneration of a Medicinal Plant Harshringar,Bangladesh Journals Online,22(2);137-142.

4] Ghiware N.B.,and Nesari T.M.,2010,Anti-Pyretic Activity of Piper nigrum and Nyctanthes arbor-tristis in Different Doses Forms, Research Journal Pharmacy and Technology,3(1)

5] Girach R.D.,Aminuddin,1994,Ethnomedicinal Studies on Harshringar-A Less Known Medicinal Plant in Unani Medicines,Hamdard Med.,37(2);60-66.

6] Jain S.K.,1991,Dictionary of Folk Medicines and Ethnobotany,Deep Publication;pp.132.

7] Kirtikar K.R.,Basu B.D.,2000,Indian Medicinal Plants,vol. VII,Sri Satguru Publication,New Delhi;pp.21102113. 
8] Nadkerni A.K.,1982,Indian Materia Medica (Dr.K.M.Nadkerni),vol.1,edition-III;857-858.

9] Pattanaik Chiranjibi,Das Rasmita,2007,Traditional Medicinal Practices Among The Tribal People of Malkangiri District,Orissa,India,Natural Product Radience,6(5);430-435.

10] Priya K.,Ganjewala Deepak,2007, The Anti-Bacterial Activities and Phytochemical Analysis of Different Plant Parts of Nyctanthes arbor-tristis Linn.,Research Journal of Phytochemistry,1;61-67.

11] Rani Champa,Chawla Sunaina,Mangal Manisha,2012,Nyctanthes arbor-tristis Linn.-A Sacred Ornamental Plant With Immense Medicinal Potentials,Indian Journal of Traditional Knowledge,11(3);427-435.

12] Rout G.R.,Mahato A.,Senapati S.K.,2007,In-vitro Clonal Propagation of Nyctanthes arbor-tristis Linn.-A Medicinal Tree, The Agricultural Journal,(2);84-89.

13] Saikia Bipul,Saikia N.,2008,Medico-Ethnobotany of Bodo Tribals in Gohpur of Sonitpur District,Assam,Indian Journal of Traditional Knowledge,9(1);52-54.

14] Saha R.K.,Acharya Srijan,2012,Biochemical Investigations and Biological evaluations of the Methanolic Extract of the Leaves of Nyctanthes arbor-tristis in-vitro,Asian Pacific Journal of Tropical Biomedicines,3(2);1534-1541.

15] Sandhya Kumar T.D.,Sudha Madhuri T.D.,Subba Rao K.,2012,Thr Anti-oxidant and Anticancer Activity of Nyctanthes arbor-tristis,International Journal of Pharmacy and Pharmaceutical Sciences,4(4). 